\title{
Kinetic fragility and structure of lithium borophosphate glasses analysed by 1D/2D NMR
}

\author{
Laura Muñoz-Senovilla ${ }^{1}$, Gregory Tricot ${ }^{2}$, Francisco Muñoz ${ }^{1}$ \\ ${ }^{1}$ Insituto de Cerámica y Vidrio (CSIC), Kelsen 5, 28049 Madrid, Spain \\ ${ }^{2}$ LASIR UMR CNRS 8516, Université de Lille 1, 59655 Villeneuve d'Ascq Cedex,
}

France

\begin{abstract}
Macroscopic and high temperature properties of lithium borophosphate glasses were determined in this contribution. Our data, obtained on $50 \mathrm{Li}_{2} \mathrm{O}-\mathrm{xB}_{2} \mathrm{O}_{3}-(50-\mathrm{x}) \mathrm{P}_{2} \mathrm{O}_{5}$ glasses, confirm a continuous and linear increase of the glass transition temperature with the B/P substitution but show a two-domain evolution for the kinetic fragility with a steep decrease in the low $\mathrm{B}_{2} \mathrm{O}_{3}$ region $(0 \leq \mathrm{x} \leq 10)$ followed by a moderate increase for higher $\mathrm{B}_{2} \mathrm{O}_{3}$ contents. In order to understand these different behaviours, the glass structure was investigated in details using $1 \mathrm{D}$ and $2 \mathrm{D}{ }^{11} \mathrm{~B} /{ }^{31} \mathrm{P}$ correlation solid state nuclear magnetic resonance. The local and medium orders of borate units were determined by 1D MASNMR, 2D ${ }^{11} \mathrm{~B}$ DQSQ- and ${ }^{11} \mathrm{~B}\left({ }^{31} \mathrm{P}\right) \mathrm{D}-\mathrm{HMQC}$ NMR experiments. The latter NMR technique was also used to deeply interpret the $1 \mathrm{D}{ }^{31} \mathrm{P}$ MAS-NMR spectra. Altogether the data allow (i) highlighting the presence of four borate and seven phosphate units, (ii) evaluating the number of homopolar POP and mixed POB linkages, and (iii) contribute to a better understanding of the $\mathrm{T}_{\mathrm{g}}$ and kinetic fragility evolution.
\end{abstract}

Keywords: Boro-Phosphate Glasses; Properties; Viscosity; Fragility; NMR *Corresponding authors E-mail: fmunoz@icv.csic.es / gregory.tricot@ univ-lille1.fr 


\section{Introduction}

Phosphate based glasses have recently gained notable attention, not only with respect to their fundamental interest but also because of the important technical applications (medical fibres, laser glasses, low temperature sealing glasses [1-2]) they are involved in. In these glass formulations, $\mathrm{P}_{2} \mathrm{O}_{5}$ is usually accompanied by another glass forming oxide (GFO) like $\mathrm{B}_{2} \mathrm{O}_{3}$ or $\mathrm{Al}_{2} \mathrm{O}_{3}$. It was indeed showed that both boric and aluminium oxides, even used at low amounts, counterbalance the main limitation of phosphate based glasses that is their poor chemical durability (i.e. their low resistance against water attack). These 'mixed' network glasses, whose structural backbone is formed by interconnected forming polyhedra, present interesting properties resulting from a synergic effect between the two GFO. One of the most striking effects of mixed glass network was observed in 1985 by Magistris et al. [3] on lithium borophosphate. In a constant $\mathrm{Li}_{2} \mathrm{O}$ content system, P/B substitution induced a non-linear evolution of the ionic conductivity leading to a strong and unexpected enhancement of that property. Owing to this interesting result, macroscopic characteristics but also structure of borophosphate glasses were extensively studied [3-9]. The structural characterisation has recently benefited from new insights coming from nuclear magnetic resonance (NMR) spectroscopy, this technique being able to analyse both local and medium range orders through the editing of 1D and 2D correlation NMR spectra [5-9].

While the study of borophosphate glass networks can appear completed, it turns out that the high temperature behaviour of these mixed network glasses has not been properly addressed. Only sparse data were published by Gaylord et al. on the properties of sodium borophosphate glasses that showed a decrease of both kinetic fragility and viscosity activation energy in the $\mathrm{NaPO}_{3}-\mathrm{Na}_{2} \mathrm{~B}_{4} \mathrm{O}_{7}$ glass system [10]. 
In this contribution, glass transition temperature $\left(\mathrm{T}_{\mathrm{g}}\right)$, viscosity, kinetic fragility and activation energy of borophosphate based glasses were measured to determine their composition dependence. Lithium borophosphate system was chosen for that study and samples were prepared with a constant $\mathrm{Li}_{2} \mathrm{O}$ content and various $\mathrm{P} / \mathrm{B}$ ratios in the $50 \mathrm{Li}_{2} \mathrm{O}-\mathrm{xB}_{2} \mathrm{O}_{3}-(50-\mathrm{x}) \mathrm{P}_{2} \mathrm{O}_{5}$ composition line. The obtained data were analysed at the light of high field $(18.8 \mathrm{~T})$ 1D/2D NMR results. The nature of the borate polyhedra, present under tri- $\left({ }^{[3]} \mathrm{B}\right)$ or tetra- $\left({ }^{[4]} \mathrm{B}\right)$ coordinated species, were determined by ${ }^{11} \mathrm{~B} 1 \mathrm{D}$ MAS-NMR and the presence of $\mathrm{BOB}$ and BOP bonds were investigated with the 2D ${ }^{11} \mathrm{~B} /{ }^{11} \mathrm{~B}$ and ${ }^{11} \mathrm{~B} /{ }^{31} \mathrm{P}$ correlation maps obtained with the ${ }^{11} \mathrm{~B}$ double quantum- single quantum (DQ-SQ [11-13]) and ${ }^{11} \mathrm{~B}\left({ }^{31} \mathrm{P}\right)$ dipolar heteronuclear multiple quantum coherence (D-HMQC [14-15]) NMR techniques. The $1 \mathrm{D}{ }^{31} \mathrm{P}$ MAS-NMR spectra were deeply interpreted owing to the data extracted from the $2 \mathrm{D}{ }^{11} \mathrm{~B} /{ }^{31} \mathrm{P}$ maps that highlighted the phosphate species involved in POB linkages. Altogether the NMR data allowed describing the borophosphate network in detail and evaluating the number of POP and POB bonds all along the composition line. The structural data were finally used to discuss the continuous modifications of $\mathrm{T}_{\mathrm{g}}$ and the non-linear changes of the kinetic fragility.

\section{Experimental}

Lithium borophosphate glasses with compositions $50 \mathrm{Li}_{2} \mathrm{O}-\mathrm{xB}_{2} \mathrm{O}_{3}-(50-\mathrm{x}) \mathrm{P}_{2} \mathrm{O}_{5}$ were prepared by conventional melt-quenching process as described in detail in reference [4]. Reagent grade raw materials, $\mathrm{Li}_{2} \mathrm{CO}_{3}, \mathrm{~B}_{2} \mathrm{O}_{3}$ and $\left(\mathrm{NH}_{4}\right)_{2} \mathrm{HPO}_{4}$, were thoroughly mixed and the batches were first calcined in porcelain crucibles up to $450^{\circ} \mathrm{C}$ in an electric furnace, then melted during $1 \mathrm{~h}$ at temperatures ranging from $800^{\circ} \mathrm{C}$ to $900^{\circ} \mathrm{C}$ depending on composition. The melts were poured onto brass moulds and annealed slightly above their glass transition temperature. Transparent and homogeneous glasses were obtained 
following this procedure for $0 \leq x \leq 20$ and $x=50$. The other compositions were affected by crystallisation during the quenching stage. Contamination by $\mathrm{Al}_{2} \mathrm{O}_{3}$ or $\mathrm{SiO}_{2}$ from the crucibles was considered insignificant as proven by chemical analysis of the glasses through Inductively Coupled Plasma-Emission Spectroscopy as well as by gravimetric and volumetric analysis in the glasses prepared in [4].

Glass transition temperatures were determined by Differential Thermal Analysis (DTA) in a SEIKO EXSTAR6000, TG-DTA6300, analyser using powdered samples in a platinum crucible, under static air and a constant heating rate of $10 \mathrm{~K} \cdot \mathrm{min}^{-1} . \mathrm{T}_{\mathrm{g}}$ values were obtained at the onset of the endothermic effect of the DTA pattern and the error in the determination of $\mathrm{T}_{\mathrm{g}}$ was assumed to be within $\pm 2 \mathrm{~K}$.

Viscosity-temperature curves of the glasses were determined by rotation and beambending methods as described in detail previously in [16]. A high-temperature Haake viscometer of the cylindrical Searle type (Haake, Karlsruhe, Germany) equipped with a ME 1700 sensor was used to measure viscosity between $10^{3}-10^{1} \mathrm{dPa} . \mathrm{s}$, through the International Standard ISO 7884-2. Rotation speeds of 3 to $15 \mathrm{rpm}$ were used during 15 min. Three measurements were carried out at three different rotation speeds for each temperature within this range and the viscosity $(\eta)$ was calculated from the shear stress $(\tau)$ and the shear rate $(\gamma)$ applied by the viscous fluid on a rotating cylindrical platinum spindle according to the equation:

$$
\eta=\tau \gamma(\mathrm{dPa} . \mathrm{s})
$$

A viscometer VIS401 (Bähr Thermoanalyse, Germany) with a $40 \mathrm{~mm}$ open span in symmetric three point mode was employed to determine viscosity values within $10^{12.5}$ $10^{9} \mathrm{dPa}$.s range. The glass beams were heated at $2 \mathrm{~K} \cdot \mathrm{min}^{-1}$ using weights of 10 to $200 \mathrm{~g}$, and the viscosity was calculated according to the standard testing conditions DIN ISO 7884-4. 
The ${ }^{11} \mathrm{~B}$ and ${ }^{31} \mathrm{P}$ MAS-NMR acquisitions were performed on an $18.8 \mathrm{~T}$ Bruker Avance III spectrometer at 256.8 and $324.0 \mathrm{MHz}$, respectively. The experiments were conducted at a spinning frequency of $20 \mathrm{kHz}$ with a ${ }^{11} \mathrm{~B} /{ }^{31} \mathrm{P} 3.2-\mathrm{mm}$ measurement probe equipped with a B free stator. The $1 \mathrm{D}{ }^{11} \mathrm{~B}$ MAS-NMR experiments were acquired with a $1 \mu$ s pulse length ( $\pi / 12$ pulse angle), a rf strength of $40 \mathrm{kHz}$ (determined on a liquid), 32-64 transients and a recycle delay (rd) of $2 \mathrm{~s}$, allowing for quantitative measurements. The $1 \mathrm{D}{ }^{11} \mathrm{~B}$ MAS-NMR spectra were corrected for the satellite transition signals contribution. The $1 \mathrm{D}{ }^{31} \mathrm{P}$ MAS-NMR acquisitions were recorded under quantitative condition with a $2.5 \mu$ s pulse length ( $\pi / 4$ pulse angle), a radiofrequency field (rf) strength of 60 $\mathrm{kHz}, 32$ transients and a rd of $120 \mathrm{~s}$. Presence and nature of BOB bonds were investigated by the ${ }^{11}$ B DQ-SQ pulse sequence introduced by Mali et al. in 2003 [12] and further improved by Edén et al. [13] and Wang et al. [14]. The 2048( $\left.\mathrm{t}_{2}\right) * 80\left(\mathrm{t}_{1}\right)$ acquisition points were recorded under rotor-synchronised conditions $(50 \mu \mathrm{s})$ with a $\pi$ pulse length of $50 \mu \mathrm{s}, 320$ transients and a rd of $2 \mathrm{~s}$ and the homonuclear interaction was reintroduced using a $400 \mu$ s length $\mathrm{BR} 2{ }^{1}{ }_{2}$ pulse scheme $\left(\left(\mathrm{R} 2{ }^{1}{ }_{2}\right.\right.$ pulse scheme repeated 2 times then $\mathrm{R} 2^{2}{ }_{-1}$ pulses repeated 2 times) [14]. The POB linkages were analysed through the edition of $2 \mathrm{D}{ }^{11} \mathrm{~B} /{ }^{31} \mathrm{P}$ correlation maps with the $\mathrm{D}$-HMQC sequence $[15,16]$. In this pulse sequence, a selective ${ }^{11} \mathrm{~B} \pi / 2-\tau-\pi$ - $\tau$ spin echo sequence ( $\pi / 2$ pulse length of $\left.9 \mu \mathrm{s}\right)$ is modulated by two ${ }^{31} \mathrm{P} \pi / 2$ pulse of $5 \mu$ s length and the ${ }^{11} \mathrm{~B} /{ }^{31} \mathrm{P}$ dipolar (through-space) interaction is recoupled by a SR $4{ }^{2}$ pulse scheme [17] applied on the ${ }^{31} \mathrm{P}$ channel during $1 \mathrm{~ms}$. Although the D-HMQC maps show spatial proximity between the $\mathrm{P}$ and $\mathrm{B}$ atoms, the short recoupling time used here $(1 \mathrm{~ms})$ allows discussing the $\mathrm{B} / \mathrm{P}$ spatial proximity in terms of P-O-B chemical connectivity, as it was recently demonstrated by comparing 2D maps recorded on borophosphate glasses with dipolar- (through space) and scalar(through bonds) HMQC techniques [18]. The 1024x24 acquisition points were recorded 
using a rotor synchronised $\mathrm{t}_{1}$-increment $(50 \mu \mathrm{s}), 128$ transients and a rd of $2 \mathrm{~s}$. The ${ }^{11} \mathrm{~B}$ and ${ }^{31} \mathrm{P}$ chemical shift values were referred to solid $\mathrm{NaBH}_{4}$ and liquid $\mathrm{H}_{3} \mathrm{PO}_{4}(85 \%)$ at 42.06 and $0 \mathrm{ppm}$, respectively.

\section{Results}

\subsection{Fragility and activation energy for viscous flow}

The viscosity data points determined on the $50 \mathrm{Li}_{2} \mathrm{O}-\mathrm{xB}_{2} \mathrm{O}_{3}-(50-\mathrm{x}) \mathrm{P}_{2} \mathrm{O}_{5}$ glasses are presented in Fig. 1 versus the temperature and the $\mathrm{T}_{\mathrm{g}} / \mathrm{T}$ parameter, with data for the $\mathrm{x}=0$ glass being taken from reference [16]. The experimental results are accompanied by their fits obtained with the viscosity model proposed by Mauro-Yue-Ellison-GuptaAllan (MYEGA) [19]. The kinetic fragility (m) of the glasses was determined from Fig. 1 and represented as a function of the boron content in Fig. 2a. The fragility follows a two-domain evolution with a strong decrease in the low $\mathrm{B}_{2} \mathrm{O}_{3}$ contents region (0-10 mol $\%$ ) followed by a moderate increase for $\mathrm{B}_{2} \mathrm{O}_{3}$ contents higher than $10 \mathrm{~mol} \%$. The $\mathrm{T}_{\mathrm{g}}$ evolution is reported in Fig. 2b. As already reported in case of borophosphate systems [4-9], B/P substitution induces significant changes in the $T_{g}$, this latter showing an almost continuous and linear increase of ca. $100{ }^{\circ} \mathrm{C}$ between the $\mathrm{LiPO}_{3}$ glass and the $\mathrm{x}=20$ mol $\% \mathrm{~B}_{2} \mathrm{O}_{3}$ composition. Finally, in an attempt to get insights into the mechanism of viscous flow, the apparent activation energy was determined by means of the Arrhenius fits of viscosity points in the low and high temperature ranges (Fig. 3). While the high temperature activation energy (low viscosity range) increases almost linearly with the $\mathrm{B}_{2} \mathrm{O}_{3}$ content, the low temperature energy counterpart (high viscosity range) decreases in the $0-10 \mathrm{~mol} \% \mathrm{~B}_{2} \mathrm{O}_{3}$ range before reaching a plateau for higher $\mathrm{B}_{2} \mathrm{O}_{3}$ contents.

\subsection{Structure by high-field Nuclear Magnetic Resonance}


The $1 \mathrm{D}{ }^{11} \mathrm{~B}$ and ${ }^{31} \mathrm{P}$ MAS-NMR spectra are reported in Fig. 4. The high magnetic field used for the ${ }^{11} \mathrm{~B}$ NMR analysis (Fig. 4a) allowed for a clear distinction between the ${ }^{[3]} \mathrm{B}$ and ${ }^{[4]} \mathrm{B}$ regions and thus for a quick and efficient $\mathrm{N}_{4}$ ratio $\left({ }^{[4]} \mathrm{B} /\left({ }^{[4]} \mathrm{B}+{ }^{[3]} \mathrm{B}\right)\right)$ determination by signal integration performed on the corrected spectra. Fig. 5 shows a high $\mathrm{N}_{4}$ ratio close to 1 that slightly decreases to 0.83 when $\mathrm{B}_{2} \mathrm{O}_{3}$ reaches 20 mol \%, indicating that the borate network is dominated by tetra-coordinated species all along the investigated composition range. Deeper analysis of the ${ }^{[4]} \mathrm{B}$ speciation can be retrieved from the spectral decomposition. Two different ${ }^{[4]} \mathrm{B}$ NMR signals (denoted in the following as ${ }^{[4]} \mathrm{B}_{1}$ and ${ }^{[4]} \mathrm{B}_{2}$ ) can be observed at -3.1 and $-1 \mathrm{ppm}$, respectively. The first signal was already observed in many borophosphate based systems [20,21] and is generally assigned to a borate connected to 4 tetrahedral species $\left({ }^{[4]} \mathrm{B}(\mathrm{OP})_{4}\right.$ groups $)$ as found in the crystalline $\mathrm{BPO}_{4}$ compound. The second signal at $-1 \mathrm{ppm}$ should thus derive from the introduction of a $\mathrm{B}^{3+}$ ion in the vicinity of the ${ }^{[4]} \mathrm{B}_{2}$ atoms. This assumption is supported by the ${ }^{11} \mathrm{~B} /{ }^{11} \mathrm{~B} 2 \mathrm{D}$ correlation map recorded on the $\mathrm{x}=20$ sample (Fig. 6a) which shows ${ }^{[4]} \mathrm{B}_{2}$ autocorrelation as well as ${ }^{[4]} \mathrm{B}_{2^{-}}{ }^{[3]} \mathrm{B}$ off-diagonal correlation, indicating that ${ }^{[4]} \mathrm{B}_{2}$ is involved in the creation of $\mathrm{BOB}$ linkages. It is also noteworthy that even at high $\mathrm{B}_{2} \mathrm{O}_{3}$ amounts $\left(20\right.$ mol \%), only a weak ${ }^{[3]} \mathrm{B}^{/[3]} \mathrm{B}$ signal can be noticed, indicating that the tricoordinated borate species do not cluster to produce a planar network. Presence of a third ${ }^{[4]} \mathrm{B}$ site (denoted as ${ }^{[4]} \mathrm{B}_{3}$ ) is also suggested by the ${ }^{11} \mathrm{~B}$ MAS-NMR spectra decomposition. However, due to its low proportion, its exact nature has not been determined. The evolutions of the ${ }^{[\mathrm{x}]} \mathrm{B}$ relative proportions deduced from the spectra decompositions can be observed in Fig. 5. The data clearly show that the ${ }^{[4]} B_{3}$ and ${ }^{[3]} B$ species have only a minor impact on the borate speciation. The most important information from Fig. 5 is that, at low $\mathrm{B}_{2} \mathrm{O}_{3}$ amounts, the ${ }^{[4]} \mathrm{B}_{1}$ unit is the most abundant borate species and that 
above 15 mol\% of $\mathrm{B}_{2} \mathrm{O}_{3}$, when trigonal boron appear, ${ }^{[4]} \mathrm{B}_{2}$ becomes the most present moieties.

The ${ }^{31} \mathrm{P}$ MAS-NMR spectra are reported in Fig. 4b. As observed in many borophosphate systems [5,9], the NMR spectra do not provide clear information because of the presence of several resonances with close chemical shift values. The general evolution toward positive values indicates a phosphate network depolymerisation whit the $\mathrm{B}_{2} \mathrm{O}_{3}$ introduction. Application of ${ }^{11} \mathrm{~B} /{ }^{31} \mathrm{P}$ correlation NMR has shown its efficiency for a detailed analysis of the broad ${ }^{31} \mathrm{P}$ NMR spectra by indicating new information about the phosphate sites connected to borate moieties [5,9]. The $2 \mathrm{D}{ }^{11} \mathrm{~B} /{ }^{31} \mathrm{P}$ correlation maps recorded on our system are presented in Fig. 6 b-d. As shown by Fig. 6 , the ${ }^{[4]} B_{1}$ site correlates with $\mathrm{P}$ atoms to create $\mathrm{POB}$ bonds in a good agreement with the presence of ${ }^{[4]} \mathrm{B}(\mathrm{OP})_{4}$ groups in the network. On the $\mathrm{x}=15$ sample, the ${ }^{[4]} \mathrm{B}_{1} / \mathrm{P}$ signal is accompanied by ${ }^{\left[{ }^{[4]}\right.} \mathrm{B}_{2} / \mathrm{P}$ correlation indicating that the second tetra-coordinated borate is also involved in POB linkages. The third correlation signal is related to ${ }^{[3]} \mathrm{B}$ signal (Fig. 6c-d) and shows that trigonal borate mix with phosphate to create mixed linkages. In order to afford new information about the phosphate network structure, the ${ }^{31} \mathrm{P}$ projections of the 2D maps were decomposed with a minimum number of components (Fig. 7a). Four different components can be observed all along the compositional range. A first signal is present at -15 ppm for low $\mathrm{B}_{2} \mathrm{O}_{3}$ content sample and can be assigned to a $\mathrm{Q}^{1}{ }_{1 \mathrm{~B}}$ species (a phosphorous connected to one $\mathrm{P}$ and one $\mathrm{B}$ atoms) from previous 1D/2D NMR study on lithium borophosphate system [7]. Moreover, presence of $\mathrm{Q}^{1}{ }_{1 \mathrm{~B}}$ can result from reactivity between a $\mathrm{Q}^{2}$ (structure of the $\mathrm{x}=0$ glass) and a $\mathrm{B}$ atoms through the replacement of a POP by a POB linkage. A low intensity component can be observed at $-25 \mathrm{ppm}$ for the low $\mathrm{B}_{2} \mathrm{O}_{3}$ sample. This site was assigned to $\mathrm{Q}^{1}{ }_{2 \mathrm{~B}}$ species because of the shielded chemical shift values compared to the $\mathrm{Q}^{1}{ }_{1 \mathrm{~B}}$ resonance. Two other components appear 
for the $\mathrm{x}=15$ and 20 samples at -9 and $-1 \mathrm{ppm}$. Their deshielded chemical shift values compared to the $\mathrm{Q}^{1}{ }_{1 \mathrm{~B}}$ species indicate a $\mathrm{Q}^{0}{ }_{\mathrm{nB}}$ structure. From previous publications [7], the two sites at -1 and -9 ppm were assigned to $\mathrm{Q}^{0}{ }_{1 \mathrm{~B}}$ and $\mathrm{Q}^{0}{ }_{2 \mathrm{~B}}$, respectively. The obtained NMR parameters (chemical shift and width) deduced from the simulations of the ${ }^{31} \mathrm{P} 2 \mathrm{D}$ map projections were then used as input parameters for the decomposition of the 1D ${ }^{31} \mathrm{P}$ MAS-NMR spectra (Fig. 7b). In addition to the previously determined signals corresponding to phosphate connected to boron species (displayed in grey in Fig. 7b), three signals corresponding to $\mathrm{Q}^{3}, \mathrm{Q}^{2}$ and $\mathrm{Q}^{1}$ of the binary $\mathrm{Li}_{2} \mathrm{O}-\mathrm{P}_{2} \mathrm{O}_{5}$ system were added in the simulations [20]. All the parameters deduced from the $1 \mathrm{D}{ }^{31} \mathrm{P}$ MAS-NMR spectra simulations are reported in Tab. 2. The evolution of the different phosphate sites are reported in Fig. 8a. For sake of clarity, $\mathrm{Q}^{3}$ and $\mathrm{Q}^{1}{ }_{2 \mathrm{~B}}$ sites, whose proportions are always lower than $5 \%$, are not represented in the figure. Fig. 8a shows a significant modification of the phosphate units present in the glass network. The sites from the binary system (not attached to $B$ ) are replaced by mixed units, with the $\mathrm{Q}^{1}{ }_{1 \mathrm{~B}}$ becoming the most important species at $\mathrm{x}=10$. For higher $\mathrm{B}_{2} \mathrm{O}_{3}$ amount, other mixed species arise indicating that the glass network evolves from a phosphate to a borophosphate one. Another parameter suitable to follow the evolution of the glass network is the number of POP and POB linkages. These two parameters were evaluated from the relative proportions and assignment of the six phosphate units (Tab. 2) and are reported in Fig. 8b. Meanwhile the replacement of POP and POB is confirmed by these data, Fig. $8 \mathrm{~b}$ also suggests that the glass network is mainly formed by POP bonds for $\mathrm{x}<10 \mathrm{~mol} \%$, but is essentially composed by mixed POB bonds for higher $\mathrm{B}_{2} \mathrm{O}_{3}$ contents (> $10 \mathrm{~mol} \%$ ).

\section{Discussion}


During the last decade, the structure of borophosphate based glasses has been widely investigated in order to understand the synergistic effect obtained by mixing $\mathrm{B}_{2} \mathrm{O}_{3}$ and $\mathrm{P}_{2} \mathrm{O}_{5}$ oxides. Major contributions to this topic were provided by solid state NMR, which was able to provide information about the nature of the borate and phosphate groups but also on their organisation at the intermediate length scale. In 2011, a NMR protocol was used to qualitatively describe the different structural units found in lithium borophosphate glasses [7]. Here this protocol was used and extended to propose a quantitative description of the network. In our $50 \mathrm{Li}_{2} \mathrm{O}-\mathrm{xB}_{2} \mathrm{O}_{3}-(50-\mathrm{x}) \mathrm{P}_{2} \mathrm{O}_{5}$ composition line, NMR data show the presence of four different borate species (Tab. 1, Fig. 5) and seven phosphate groups (Tab. 2, Fig. 8). While B/P mixing was highlighted by the strong decrease of the pristine $\mathrm{Q}^{2}$ units replaced by mixed $\mathrm{Q}^{1}{ }_{1 \mathrm{~B}}, \mathrm{Q}^{1}{ }_{2 \mathrm{~B}}$ and $\mathrm{Q}^{0}{ }_{\mathrm{xB}}$ species, the borate network also shows major rearrangements with the appearance of new ${ }^{[4]} \mathrm{B}$ signals but also trigonal borate moieties. Our study shows that the $\mathrm{B} / \mathrm{P}$ substitution strongly impacts both local and medium range orders and is thus expected to have a significant effect on the material properties as well. However it is noteworthy that the planar ${ }^{[3]} \mathrm{B}$ species is only present at low amounts (Tab.1, Fig. 5) and do not mixed together to form planar network (Fig. 6a) that would strongly affect the global network dimensionality. Therefore, it is likely to believe that this species is probably not at the origin of the strong property modifications observed in our materials.

Usually the introduction of boron in the formulation (through addition in a phosphate matrix or by P/B substitution) is found to significantly increase the glass transition temperature [3-10]. Our study fully confirms this general observation through the almost linear and continuous $T_{g}$ evolution reported in Fig. $2 b$. However, while the $T_{g}$ increase is usually related to the formation of $\mathrm{B}(\mathrm{OP})_{4}$ groups that increase the global network reticulation, the new data presented in Fig. $8 \mathrm{~b}$ suggest that the $\mathrm{T}_{\mathrm{g}}$ increase could be 
ruled by the overall number of mixed POB linkages. This relationship between the linkage nature and the $T_{g}$ evolution could also explain why $T_{g}$ still increases in the $10-20$ mol\% range when $\mathrm{B}(\mathrm{OP})_{4}$ groups $\left({ }^{[4]} \mathrm{B}_{1}\right.$ site) decrease (in percentage but also in absolute number) at the expenses of ${ }^{[4]} \mathrm{B}_{2}$ groups. A completely different structural feature should be at the origin of the kinetic fragility parameter evolution. As shown in Fig. 2a, m follows a different evolution than $\mathrm{T}_{\mathrm{g}}$, the former experiencing a two-domain evolution with a separation between the two domains found for the $\mathrm{x}=10$ sample. No noticeable change can be observed for that particular composition in Fig. 5 and 8a indicating that neither the borate nor phosphate networks experience dramatic changes that could explain the non-linear evolution of the kinetic fragility.

Using the borate speciation obtained from the ${ }^{11} \mathrm{~B}$ MAS-NMR experiments, the average bonding energy of each glass composition was calculated from values taken from the works of Dimitrov et al. [21,22] that assigned an energy of 373, 464 and $498 \mathrm{~kJ} / \mathrm{mol}$ to P-O bonds, B-O bonds in ${ }^{[4]} \mathrm{B}$ and $\mathrm{B}-\mathrm{O}$ bonds in ${ }^{[3]} \mathrm{B}$, respectively. The evolution of the overall energy versus the composition is reported in Fig. 9. While again a two-domain evolution can be found in this figure, the breaking point is not observed for the $\mathrm{x}=10 \mathrm{but}$ for $\mathrm{x}=15$ sample, suggesting that the bond energy is not the dominating effect inducing the non-linear evolution observed for the kinetic fragility.

While no particular structural parameter has been identified as the origin the twodomain evolution of the kinetic fragility, comparison between Figs.2b and 8b may suggest that the overall nature of the network could play this role. Indeed, it is noteworthy that for $\mathrm{B}_{2} \mathrm{O}_{3}$ amounts lower than $10 \mathrm{~mol} \%$ (when m experiences a strong decrease), the dominating linkage is the homopolar POP bonds whereas POB bonds dominate for higher $\mathrm{B}_{2} \mathrm{O}_{3}$ contents (when $\mathrm{m}$ does not decrease anymore). In other words, our study 
suggests that kinetic fragility evolution could be related to the nature of the glass network.

If one looks at the liquid in equilibrium, the activation energy for the viscous flow, as calculated from the Arrhenius fits of the viscosity data points, shows a linear increase with the boron content in the glasses. A higher content of $\mathrm{B}_{2} \mathrm{O}_{3}$ induces the formation of boron species of the type ${ }^{[4]} \mathrm{B}$ mainly due to the enough amount of modifier lithium ions present that may compensate the excess negative charge of these four-fold coordinated boron groups. Thus, upon cooling from the melts, the viscosity of the liquid increases and it does so at a higher rate for higher contents of boron, i.e. with higher activation energy, which is explained through the fact that higher boron content induces the formation of higher number of ${ }^{[4]} \mathrm{B}$ groups that increase the overall network connectivity. Within the compositional range studied, the content of ${ }^{[4]} \mathrm{B}$ groups is very close to $100 \%$ up to $15 \mathrm{~mol} \% \mathrm{~B}_{2} \mathrm{O}_{3}$ and so the activation energy of viscosity of the liquids is proportional to the content of ${ }^{[4]} \mathrm{B}$.

In a recent paper by Muñoz et al. on binary metaphosphate glasses [26], the authors demonstrated a close relationship between the structure determined in the glasses and the value of the activation energy of the melts, and concluded that the strength of the bonds between modifier cations and the network units determines the rate of increase of viscosity upon cooling. Thus, higher rate of increase of viscosity, i.e. higher activation energy, gives rise to a smaller change of the structure of the glass as compared to that of the liquid from which it has been formed and, what is more important, the fragility of the glass is governed through the structural arrangement that takes place upon cooling. We may then extrapolate the same reasoning to the way the fragility of the lithium borophosphate glasses is governed through the composition. The $\mathrm{B}_{2} \mathrm{O}_{3}$ content gives rise to the formation of ${ }^{[4]} \mathrm{B}$ units, which number controls the viscosity increase upon 
cooling the melt and increases the overall network connectivity that is at the origin of the decrease of fragility.

On the other hand, the apparent activation energy calculated at the high viscosity part of the curves presents a quite similar behaviour as that of the fragility. When determining the viscosity points at this region, the undercooled liquids may present a smaller or bigger rate of decrease of viscosity with temperature, thus having different fragilities. As it can be seen in Fig. 9, the average bonding energy of the network forming elements decreases with the increase of boron up to $15 \mathrm{~mol} \% \mathrm{~B}_{2} \mathrm{O}_{3}$, which results from the lower energy of the ${ }^{[4]} \mathrm{B}-\mathrm{O}$ bonds as compared to the P-O ones. We have not taken into account however whether the $\mathrm{P}-\mathrm{O}$ bonds are attributed to a $\mathrm{Q}^{2}$ or $\mathrm{Q}^{1}$ units, as they could be considered more similar than the $\mathrm{P}-\mathrm{O}$ bonds and the $\mathrm{B}-\mathrm{O}$ ones in the same coordination state. Thus, the decrease of the activation energy of the high viscosity region of the curves may be explained through the decrease of the average bonding energy of the mixed network glasses.

\section{Conclusions}

Glasses were prepared in the $50 \mathrm{Li}_{2} \mathrm{O}-\mathrm{xB}_{2} \mathrm{O}_{3}-(50-\mathrm{x}) \mathrm{P}_{2} \mathrm{O}_{5}$ composition line to investigate the relationships between $\mathrm{Tg}$, viscosity, kinetic fragility and local/medium range structures. Both structural orders were probed using $1 \mathrm{D}$ - and $2 \mathrm{D}$ correlation- ${ }^{11} \mathrm{~B} /{ }^{31} \mathrm{P}$ NMR experiments performed at very high field $(18.8 \mathrm{~T})$. The data show the presence of four borate and seven phosphate species and allow estimating the number of POP and POB linkages. It turns out that the $x=10$ composition experiences a breakthrough in the nature bonding with a network dominated by homopolar POP linkages in the $\mathrm{x}=0-10$ range and mixed POB bonds for $x>10$. This new structural data allows explaining the $T_{g}$ 
evolution but also contributes to a better understanding of the non-linear evolution of the kinetic fragility observed in our system.

\section{Conflicts of Interest}

There are no conflicts of interest to declare.

\section{Acknowledgements}

Funding from projects MAT2010-20459 and MAT2013-48246-C2-1-P from Ministerio

de Economía y Competitividad (MINECO) of Spain is acknowledged. L. MuñozSenovilla also thanks the MINECO for her PhD scholarship (BES-2011-044130). G. Tricot thanks would like to thank Region Nord Pas de Calais, Europe (FEDER), CNRS, University of Lille and TGIR-RMN-THC FR3050 CNRS for funding.

\section{References}

[1] A.J. Parsons, N. Sharmin, Sharifah I.S. Shaharuddin and M. Marshall, J. Non-Cryst. Solids, 2015, 408, 76-86.

[2] I.W. Donald, J. Mater. Sci., 1993, 28, 2841-2886.

[3] A. Magistris, G. Chiodelli and M. Villa, Journal Of Power Sources, 1985, 14, 8791.

[4] F. Muñoz, L. Montagne, L. Pascual and A. Durán, J. Non-Cryst. Solids, 2009, 355, 2571-2577.

[5] S. Elbers, W. Strojek, L. Koudelka and H. Eckert, Sol. St. Nucl. Magn. Reson., 2005, 27, 65-76.

[6] D. Raskar, M.T. Rinse and H. Eckert, J. Phys. Chem. C, 2008, 112, 12530-12539. 
[7] B. Raguenet, G. Tricot, G. Silly, M. Ribes and A. Pradel, J. Mat. Chem., 2011, 21, 17693-17704.

[8] B. Raguenet, G. Tricot, G. Silly, M. Ribes and A. Pradel, Sol. St. Ionics, 2012, 208 25-30.

[9] G. Tricot, A. Saitoh and H. Takebe, Phys. Chem. Chem. Phys., 2015, 17, 2953129540.

[10] S. Gaylord, B. Tincher, L. Petit and K. Richardson, Mat. Res. Bull., 2009, 44, 1031-1035.

[12] G. Mali, G. Fink and F. Taulelle, J. Chem. Phys., 2004, 120, 2835-2845.

[12] M. Edén, D. Zhou and J. Yu, Chem. Phys. Lett., 2006, 431, 397-403.

[13] Q. Wang, B. Hu, O. Lafon, J. Trebosc, F. Deng and J.P. Amoureux, J. Magn. Res., 2009, 200, 251-260.

[14] Z. Gan, J. Magn. Res., 2007, 184, 39-43.

[15] G. Tricot, J. Trébosc, F. Pourpoint, R. Gauvin and L. Delevoye, Ann. Rep. NMR Spectr. 2014, 81, 145-184.

[16] L. Muñoz-Senovilla and F. Muñoz, J. Non-Cryst. Solids, 2014, 385, 9-16.

[17] A. Brinkmann, A. Kentgens, J. Am. Chem. Soc., 2006, 128, 14758-14759.

[18] G. Tricot, B. Raguenet, G. Silly, M. Ribes, A. Pradel, and H. Eckert, Chem. Comm., 2015, 51, 9284-9286.

[19] J.C. Mauro, Y. Yue, A.J. Ellison, P. K. Gupta and D.C. Allan, Proc. Natl. Acad. Sci. U.S.A., 2009, 106, 19780-19784.

[20] L. van Wullen, H. Eckert, and G. Schwering, Chem. Mat., 2000, 12, 1840-1846.

[21] V. Dimitrov and T. Komatsu, J. Non-Cryst. Solids, 2010, 356, 258-262.

[22] V. Dimitrov and T. Komatsu, J. Chem. Technol. Met., 2012, 50, 387-396.

[22] C. Hermansen, J.C. Mauro and Y. Yue, J. Chem. Phys., 2014, 140, 154501. 
[23] D.L. Sidebottom, J. Chem. Phys., 2015, 142, 107103.

[24] C. Hermansen, J.C. Mauro and Y. Yue, J. Chem. Phys., 2015, 142, 107104.

[25] A.I. Fu and J.C. Mauro, J. Non-Cryst. Solids, 2013, 361, 57-62.

[26] F. Muñoz, L. Muñoz-Senovilla, J. Non-Cryst. Solids, 2017, 471, 142-145.

Tab. 1: ${ }^{11} \mathrm{~B}$ NMR parameters: chemical shift $\left(\delta_{\text {iso, }}+/-0.1 \mathrm{ppm}\right)$, full width at half maximum (FWHM, +/- $0.2 \mathrm{ppm})$, quadrupolar constant $\left(\mathrm{C}_{\mathrm{Q}},+/-0.1 \mathrm{MHz}\right)$, asymmetry parameter $\left(\eta_{\mathrm{Q}},+/-0.1\right)$ and relative proportions (rel. prop., $\left.+/-2 \%\right)$.

\begin{tabular}{|c|c|c|c|c|c|c|c|c|c|}
\hline $\begin{array}{c}\mathrm{x} \\
/ \mathrm{mol} \% \\
\end{array}$ & ${ }^{[4]} \mathbf{B}_{\mathrm{x}}$ & $\begin{array}{c}\text { Siso } \\
\text { /ppm }\end{array}$ & $\begin{array}{l}\text { fwhm } \\
/ \text { ppm }\end{array}$ & $\begin{array}{c}\text { rel. prop. } \\
/ \%\end{array}$ & ${ }^{[3]} \mathbf{B}$ & $\begin{array}{c}\text { Siso } \\
\text { / ppm }\end{array}$ & $\begin{array}{c}\mathrm{C}_{\mathbf{Q}} \\
/ \mathrm{MHz} \\
\end{array}$ & $\eta_{Q}$ & $\begin{array}{c}\text { rel. prop. } \\
/ \%\end{array}$ \\
\hline 5 & ${ }^{[4]} \mathbf{B}_{1}$ & -3.1 & 2.1 & 100 & ${ }^{[3]} \mathbf{B}$ & - & - & - & - \\
\hline \multirow[t]{2}{*}{10} & ${ }^{[4]} \mathbf{B}_{1}$ & -3.1 & 2.0 & 82 & ${ }^{[3]} \mathbf{B}$ & - & - & - & - \\
\hline & ${ }^{[4]} \mathbf{B}_{2}$ & -1.1 & 1.9 & 18 & & & & & \\
\hline \multirow[t]{2}{*}{15} & ${ }^{[4]} \mathbf{B}_{1}$ & -3.1 & 1.8 & 48 & ${ }^{[3]} \mathbf{B}$ & 15.6 & 2.7 & 0.2 & 4 \\
\hline & ${ }^{[4]} \mathbf{B}_{2}$ & -1.0 & 1.8 & 48 & - & - & - & - & - \\
\hline \multirow[t]{3}{*}{20} & ${ }^{[4]} \mathbf{B}_{1}$ & -2.8 & 1.8 & 18 & ${ }^{[3]} \mathbf{B}$ & 17.1 & 2.87 & 0.6 & 17 \\
\hline & ${ }^{[4]} \mathbf{B}_{2}$ & -0.8 & 2.0 & 60 & & & & & \\
\hline & ${ }^{[4]} \mathbf{B}_{3}$ & 0.8 & 1.5 & 5 & & & & & \\
\hline
\end{tabular}


Tab. 2: ${ }^{31} \mathrm{P}$ NMR parameters: chemical shift $\left(\delta_{\text {iso, }}+/-0.1 \mathrm{ppm}\right)$, full width at half maximum (FWHM, +/- $0.2 \mathrm{ppm}$ ) and relative proportions (rel. prop., +/- 2\%). The NMR parameters deduced from the simulations of the ${ }^{31} \mathrm{P}$ projections of the ${ }^{11} \mathrm{~B} /{ }^{31} \mathrm{P} 2 \mathrm{D}$ maps are reported into brackets.

\begin{tabular}{|c|c|c|c|c|c|c|c|c|}
\hline $\begin{array}{c}\mathbf{x} \\
/ \mathrm{mol} \%\end{array}$ & $Q^{n}$ & $\begin{array}{c}\delta_{\text {iso }} \\
/ \mathrm{ppm}\end{array}$ & $\begin{array}{c}\text { FWHM } \\
\text { / ppm }\end{array}$ & $\begin{array}{l}\text { Rel. prop. } \\
/ \%\end{array}$ & $Q^{n}$ & $\begin{array}{c}\delta_{\text {iso }} \\
/ \mathbf{p p m}\end{array}$ & $\begin{array}{c}\text { FWHM } \\
\text { / ppm }\end{array}$ & $\begin{array}{l}\text { Rel. prop. } \\
/ \%\end{array}$ \\
\hline 5 & $Q_{1 B}^{I}$ & $-14.5(-14.8)$ & $9.0(8.9)$ & 26 & $\begin{array}{l}Q^{3}{ }_{0} \\
Q^{2}{ }_{0} \\
Q^{1}{ }_{0}\end{array}$ & $\begin{array}{l}-31.3 \\
-21.6 \\
-4.1\end{array}$ & $\begin{array}{c}10.8 \\
9.7 \\
6.7\end{array}$ & $\begin{array}{c}4 \\
62 \\
8\end{array}$ \\
\hline 10 & $\begin{array}{l}Q_{1 B}^{l} \\
Q^{l}{ }_{2 B}\end{array}$ & $\begin{array}{l}-13.2(-13.2) \\
-23.7(-23.2)\end{array}$ & $\begin{array}{l}9.6(9.6) \\
9.1(9.0)\end{array}$ & $\begin{array}{l}54 \\
5\end{array}$ & $\begin{array}{l}Q^{3}{ }_{0} \\
Q^{2}{ }_{0} \\
Q^{1}{ }_{0}\end{array}$ & $\begin{array}{l}-29.2 \\
-20.2 \\
-3.3\end{array}$ & $\begin{array}{l}8.1 \\
9.7 \\
6.3\end{array}$ & $\begin{array}{c}2 \\
26 \\
13\end{array}$ \\
\hline 15 & $\begin{array}{l}Q^{l}{ }_{1 B} \\
Q^{1}{ }_{2 B} \\
Q^{0}{ }_{2 B}\end{array}$ & $\begin{array}{c}-12.3(-12.1) \\
-20.8(-20.6) \\
-6.3(-6.1)\end{array}$ & $\begin{array}{l}9.0(9.2) \\
9.0(9.0) \\
7.5(7.5)\end{array}$ & $\begin{array}{c}50 \\
6 \\
17\end{array}$ & $\begin{array}{l}Q^{3}{ }_{0} \\
Q^{2}{ }_{0} \\
Q^{1}{ }_{0}\end{array}$ & $\begin{array}{l}-27.8 \\
-18.3 \\
-1.5\end{array}$ & $\begin{array}{l}8.2 \\
9.5 \\
6.9\end{array}$ & $\begin{array}{c}2 \\
11 \\
14\end{array}$ \\
\hline 20 & $\begin{array}{l}Q^{1}{ }_{1 B} \\
Q^{1}{ }_{2 B} \\
Q^{0}{ }_{2 B} \\
Q^{0}{ }_{1 B}\end{array}$ & $\begin{array}{c}-11.2(-10.8) \\
-20.8(-20.6) \\
-6.0(-6.1) \\
-0.5(-0.5)\end{array}$ & $\begin{array}{l}9.0(9.0) \\
9.0(8.9) \\
7.6(7.6) \\
6.0(6.0)\end{array}$ & $\begin{array}{c}38 \\
1 \\
30 \\
20\end{array}$ & $\begin{array}{l}Q^{3}{ }_{0} \\
Q^{2}{ }_{0} \\
Q^{1}{ }_{0}\end{array}$ & $\begin{array}{l}-27.8 \\
-18.3 \\
-1.5\end{array}$ & $\begin{array}{l}8.2 \\
9.5 \\
6.9\end{array}$ & $\begin{array}{l}1 \\
8 \\
2\end{array}$ \\
\hline
\end{tabular}




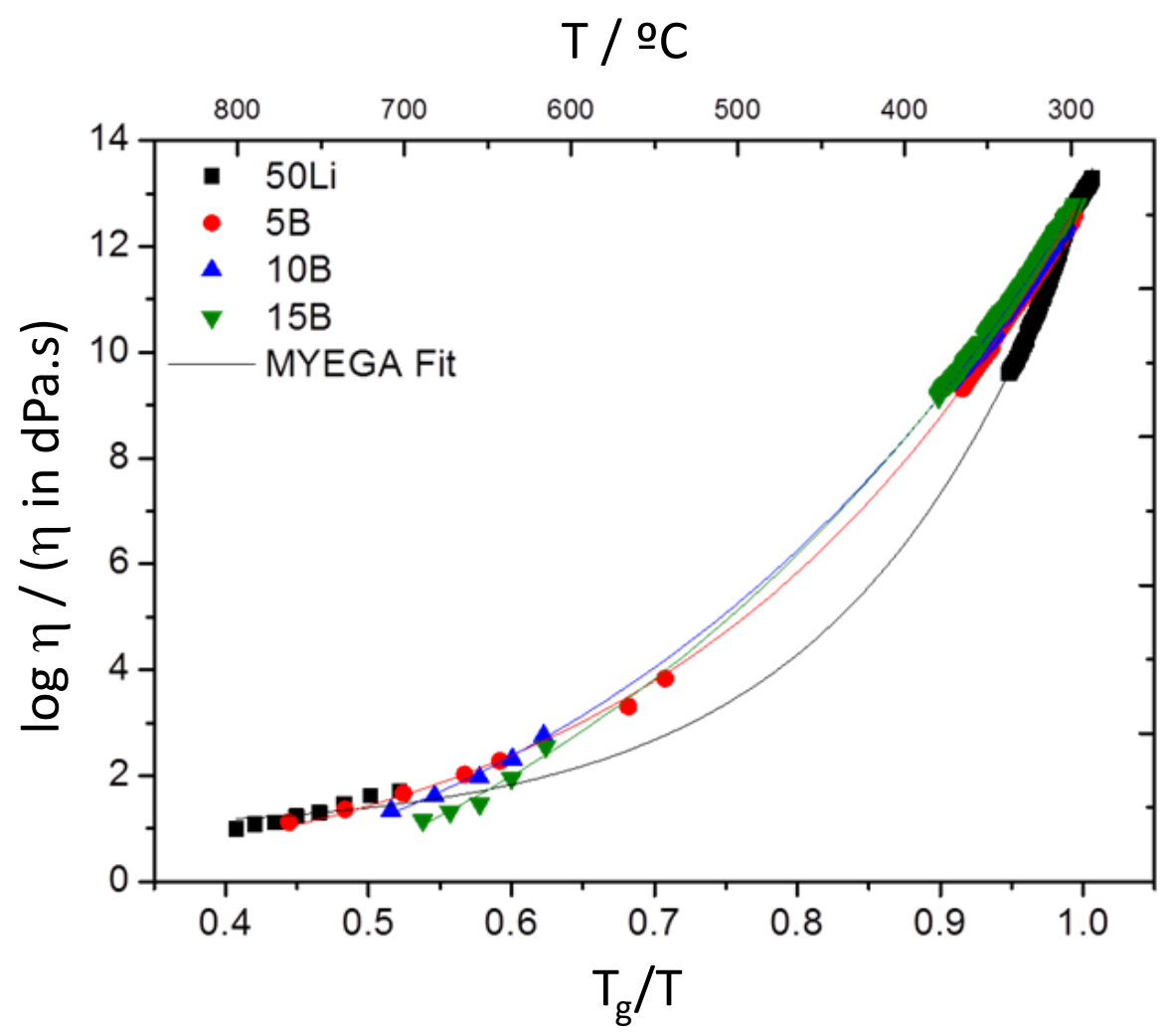

Figure 1 : Viscosity points versus the reduced temperature parameter $\mathrm{T}_{\mathrm{g}} / \mathrm{T}$. The lines show fits to MYEGA equation [19]. 




Figure 2: Kinetic fragility (a) and glass transition temperature (b) versus the $\mathrm{B}_{2} \mathrm{O}_{3}$ content of the glasses. 




Figure 3: Apparent activation energy at low and high temperature versus the $\mathrm{B}_{2} \mathrm{O}_{3}$ content of the glasses. 




(b)



Figure 4: ${ }^{11} \mathrm{~B}$ (a) and ${ }^{31} \mathrm{P}$ (b) MAS-NMR experiments performed on the glass series. The

${ }^{11} \mathrm{~B}$ NMR spectra are accompanied by decompositions in dotted lines. 




Figure 5: Relative proportions of the different borate species and $\mathrm{N}_{4}$ ratio versus the $\mathrm{B}_{2} \mathrm{O}_{3}$ content of the glasses. 
(a)


(b)



${ }^{11} \mathrm{~B}$ relative frequency / ppm

(d)



Figure 6: $2 \mathrm{D}$ correlation NMR map: ${ }^{11} \mathrm{~B} /{ }^{11} \mathrm{~B}$ obtained on the $\mathrm{x}=20$ sample $(\mathrm{a}),{ }^{11} \mathrm{~B} /{ }^{31} \mathrm{P}$ obtained on the $\mathrm{x}=5,15$ and 20 samples $(\mathrm{b}, \mathrm{c}, \mathrm{d})$. The $2 \mathrm{D}$ maps are accompanied by projections and corresponding 1D MAS NMR spectra. 
(a)





Figure 7: ${ }^{31} \mathrm{P}$ projections of the $2 \mathrm{D}{ }^{11} \mathrm{~B} /{ }^{31} \mathrm{P}$ maps showing the $\mathrm{P}$ involved in $\mathrm{POB}$ linkages (a). ${ }^{31}$ P MAS-NMR decompositions using the data of Fig. 7a (displayed in grey) as input parameters. 




Figure 8: Relative proportions of the different phosphate species (a) and total number of POP and POB linkages (b) versus the $\mathrm{B}_{2} \mathrm{O}_{3}$ content of the glasses. 




Figure 9: Bond energy versus the $\mathrm{B}_{2} \mathrm{O}_{3}$ content of the glasses. 